\title{
Multivessel coronary thrombosis in a COVID-19 patient: Lungs are not always a culprit
}

\author{
Michał Kuzemczak ${ }^{1,2,3 *}$, Charalampos Kavvouras ${ }^{1 *}$, \\ Mohammad Alkhalil ${ }^{1}$, Jonah Himelfarb ${ }^{1}$, Mark Osten ${ }^{1}$ \\ ${ }^{1}$ Peter Munk Cardiac Center, Division of Cardiology, Toronto General Hospital, \\ University Health Network, Toronto, Canada \\ ${ }^{2}$ Chair of Emergency Medicine, Department of Medical Rescue, \\ Poznan University of Medical Sciences, Poznan, Poland \\ ${ }^{3}$ Department of Invasive Cardiology, Central Clinical Hospital of the Ministry \\ of Interior and Administration, Warsaw, Poland
}

A 54-year-old man, with no cardiovascular risk factors, was admitted with 2 -hour chest pain. Five days earlier, he had been found to be coronavirus disease 2019 (COVID-19) positive, but his clinical condition had allowed him to be managed at home.

On admission, the patient was hemodynamically stable, afebrile, with no respiratory symptoms. His electrocardiogram was consistent with ST-segment elevation myocardial infarction. His complete blood count, international normalized ratio, activated partial thromboplastin time, and $\mathrm{C}$-reactive protein were normal. $\mathrm{D}$-dimer was $4400 \mu \mathrm{g} / \mathrm{L}$, ferritin was $914 \mu \mathrm{g} / \mathrm{L}$ and high sensitivity troponin I > 50000 ng/L. Neither pulmonary embolism nor COVID-19 features was detected on computed tomography.

Coronary angiography revealed an acute occlusion of the proximal left anterior descending artery (LAD) (Fig. 1A) and non-occlusive thrombus in the proximal right coronary artery (RCA). The latter artery was occluded in the second and the third posterolateral branches (Fig. 1B, C). The flow in the LAD was restored with a drug-eluting stent (Fig. 1D, E). An attempt to retrieve the RCA thrombi with a thrombectomy catheter was unsuccessful (Fig. $1 \mathrm{~F}$ ) and a decision was made to treat the patient with a bolus and 18-hour infusion of eptifibatide and dual antiplatelet therapy (acetylsalicylic acid plus ticagrelor). The patient was transferred to our dedicated COVID-19 ward in stable condition. Further in-hospital stay was uneventful.

The presented case was unique as there was a lack of either cardiovascular factors or respiratory symptoms. Previous cases of COVID-19 patients have mainly reported on multivessel coronary thrombosis in the context of severe pneumonia or multiorgan failure. The present case implies a unique hypercoagulable state associated with COVID-19 irrespective of cardiovascular risk factors and lung involvement.

Conflict of interest: None declared

Address for correspondence: Michał Kuzemczak, MD, PhD, MSc, Toronto General Hospital, Division of Cardiology, 585 University Avenue, Toronto, Ontario, M5G 2C4 Canada, tel: +1 (647) 675 4669, e-mail: michal.kuzemczak@gmail.com Received: 17.11 .2020 Accepted: 28.02.2021

*Contributed equally

This article is available in open access under Creative Common Attribution-Non-Commercial-No Derivatives 4.0 International (CC BY-NC-ND 4.0) license, allowing to download articles and share them with others as long as they credit the authors and the publisher, but without permission to change them in any way or use them commercially. 


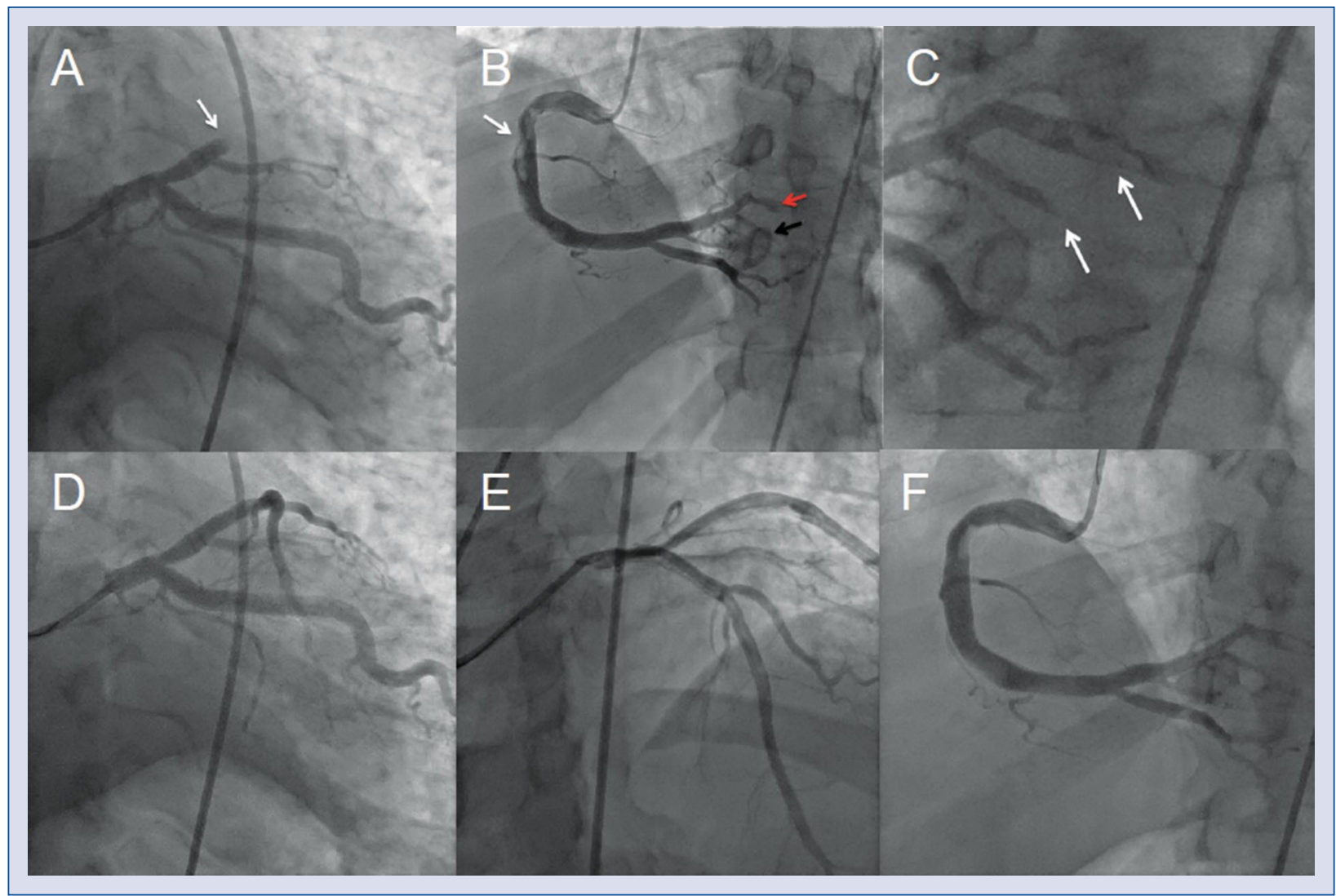

Figure 1. A. Acute occlusion of the left anterior descending artery (LAD; arrow); B. Thrombus (white arrow) in the proximal segment of the right coronary artery (RCA) and occlusion of the second (black arrow) and the third posterolateral branch (RPL; red arrow); C. Thrombus burden in the second and the third RPL (white arrows); D, E. Postprocedural left coronary angiography; F. Post-procedural right coronary angiography. 